\title{
Research of Micro-alloyed Microstructure and Composition in X80 Pipeline Steel for High Heat Input Welding
}

\author{
Jian-Ming WANG ${ }^{1, a}$, Yan LIU ${ }^{2, b,{ }^{*}, \text { Kai WANG }}{ }^{2, c}$, Yang LIU ${ }^{1, d}$ \\ ${ }^{1}$ School of Mechanical Engineering, Shenyang University, Shenyang 110044, China \\ ${ }^{2}$ The Liaoning Provincial Key Laboratory of Advanced Materials \& Preparation Technology, \\ Shenyang University, Shenyang, 110044, China \\ awjmlucky1979@163.com, bliuyanneu@163.com, 'cwkai1991@foxmail.com, \\ 'shendacaijialy@126.com \\ ${ }^{*}$ Corresponding author
}

Keywords: X80 pipeline steel, Micro-alloying, Chemical composition, Microstructure, High heat input welding.

\begin{abstract}
The characteristic of chemical composition of X80 pipeline steel, the microstructure and the existing problems under the condition of high heat input welding were introduced in this paper. The micro-alloyed process of $\mathrm{Nb}, \mathrm{Ti}, \mathrm{V}$ elements in X80 pipeline steel and the influence on the mechanical properties were respectively discussed. In addition, the reasons of the grain coarsening in the welding heat affected zone, the softening and embrittlement in partial microstructure were explored and the corresponding solutions were presented. For X80 pipeline steel, we can see that high strength and high toughness microstructure can be obtained not only by micro-alloyed, but also through the optimization of rolling process and the regulation of cooling rate after hot rolling. X80 pipeline steel with low carbon content and the appropriate micro-alloying, coupled with modern controlled rolling and controlled cooling technology, will have very high strength and toughness. Scholars mainly studied on the composite micro-alloying of $\mathrm{Nb}$ and $\mathrm{Ti}, \mathrm{Al}, \mathrm{Ti}, \mathrm{Mg}, \mathrm{Zr}$ alloy oxides and complex oxide micro-alloying and $\mathrm{Ca}$ treatment desulfurization technology, and so on.
\end{abstract}

\section{Introduction}

Pipeline transport is an economic, safe and efficient mode of transport, it can not only transport coal and other solid materials, but also can transport oil and natural gas [1]. And the demand for oil and natural gas is increasing with the rapid development of the national economy, so the demand of pipeline steel as transportation vector is also increasing. By the end of 2010, the total length of oil and gas pipelines is $85,000 \mathrm{~km}$ in our country, nearly $80 \%$ of onshore crude oil, $20 \%$ of refined oil and more than $95 \%$ of natural gas are transported through pipelines. In the coming years, with the Northwest, Northeast, Southwest, maritime 'four strategic lines of oil and gas resources' to be built [2-4], China's oil and gas transport industry also will usher in a boom in the spring. The research and development of pipeline steel is toward high levels development of large-diameter, high pressure and automation with the increase of oil and natural gas transportation capacity and transport distance [5].

This paper describes the research and application of X80 pipeline steel, which is widely used in the "West-East Gas Project" in recent years. The characteristic of chemical composition of X80 pipeline steel, the microstructure and the existing problems under the condition of high heat input welding were introduced in this paper. The micro-alloyed process of $\mathrm{Nb}, \mathrm{Ti}, \mathrm{V}$ elements in X80 pipeline steel and the influence on the mechanical properties were respectively discussed. In addition, the reasons of the grain coarsening in the welding heat affected zone, the softening and brittlement in partial microstructure were explored and the corresponding solutions were presented.

\section{Characteristics of the Chemical Composition of X80 Pipeline Steel}

Typical carbon content of X80 pipeline steel is $0.04 \%$ to $0.08 \%$, however in some special cases, 
carbon content can reach the levels of $0.02 \%$. In dealing with offshore, under extremely adverse natural conditions, such as polar, X80 pipeline steel must have low carbon equivalent, so that in the welding process, welding without preheating and post weld heat treatment are performed, and that also can ensure good toughness of welded joints, in order to prevent cracking caused by sulfur compounds. In this way, the decrease of carbon content will inevitably lead to the decrease of the mechanical properties of steel, such as hardness and yield strength.

Modern micro-alloyed technology is a micro-alloying of Mn alloying elements in X80 pipeline steel to compensate for the reduction of mechanical properties due to reduced carbon content. The principle is mainly that the lattice distortion caused by Mn element is larger than carbon in the pipeline steel, so Mn has the better solid solution strengthening effect than carbon. However, too much Mn content will accelerate the center segregation of X80 pipeline steel during hot rolling. Therefore, depending on the different thickness and strength, Mn content is generally controlled from $1.1 \%$ to $2.0 \%$ in the micro-alloying process [6].

Micro-alloying elements of pipeline steel are mainly the strong nitride-forming elements of $\mathrm{Nb}$, $\mathrm{Ti}, \mathrm{V}$, and so on. Its main function is to prevent the growth of austenite grain in the steel plate controlled rolling process and to delay the recrystallization of austenite grain in the process of rolling steel [7]. $\mathrm{Nb}$ is not only one of the leading fine-grain strengthening elements, but also have the role of moderate precipitation hardening and reducing the ductile-brittle transition temperature of steels. Therefore they added appropriately a small amount of $\mathrm{Nb}$ in HSLA steels. However, the studies [8] on the precipitates dissolution and grain growth in the HAZ for HSLA-100 steel indicated that $\mathrm{Nb}(\mathrm{C}, \mathrm{N})$ has started to dissolve at $1200^{\circ} \mathrm{C}$, austenite grain coarsening occurs, and dissolved a lot at $1300-1400^{\circ} \mathrm{C}$, austenite grain coarsening significantly. Therefore, the high strength micro-alloyed steel single used $\mathrm{Nb}$ is difficult to stand high heat input welding. For this reason many scholars are studying on $\mathrm{Nb}$ and $\mathrm{Ti}$ micro-alloying HSLA. The addition of Ti element into steel can form stable nitrides, such as $\mathrm{TiN}$, in the welding peak temperatures. TiN of fine distribution in the HAZ can prevent austenite coarsening, accelerate the formation of acicular ferrite, refine HAZ transformation product and improve the strength and toughness of HAZ. As same as Ti, $\mathrm{V}$ is one of the main strengthening elements in steel. However, the ductile-brittle transition temperature of steels containing $\mathrm{V}$ is usually higher than that of steel containing $\mathrm{Nb}$ and $\mathrm{Ti}$, So $\mathrm{V}$ as micro-alloying element is not often used individually in steel, and it is used generally with $\mathrm{Nb}$ and Ti simultaneously. VN is formed in steel, the interfacial energy between $\mathrm{VN}$ and the ferrite is lower, that is conducive to the nucleation of acicular ferrite and grain refinement, and that can improve the mechanical properties of steel.

X80 pipeline steel belongs to a high degree of 'clean steel'. Modern metallurgical techniques have been developed to ensure that the contents of impurities and gases are at a low or ultra-low level. This production level is closely related to the development of metallurgy and a variety of new technologies, such as hot metal pretreatment, BOF refining, ladle metallurgy, continuous casting, etc.

Tables 1 and 2 [9] introduced the specific conditions of the chemical composition and mechanical properties of X80 pipeline steel on 'West-East Gas Project'. Table 2 shows that the conditions of the low carbon content and the right amount of micro-alloying elements, together with the controlled rolling and controlled cooling technology, can make steel with high strength and toughness, which is unavailable on the condition of the traditional alloying process with hot rolling.

Tab. 1 Chemical compositions of X80 pipeline steel (wt \%)

\begin{tabular}{ccccccccc}
\hline $\begin{array}{c}\mathrm{C} \\
\leq 0.09\end{array}$ & $\begin{array}{c}\mathrm{Si} \\
\leq 0.42\end{array}$ & $\begin{array}{c}\mathrm{Mn} \\
\leq 1.85\end{array}$ & $\begin{array}{c}\mathrm{P} \\
\leq 0.022\end{array}$ & $\begin{array}{c}\mathrm{S} \\
\leq 0.005\end{array}$ & $\begin{array}{c}\mathrm{Cr} \\
\leq 0.45\end{array}$ & $\begin{array}{c}\mathrm{Mo} \\
\leq 0.35\end{array}$ & $\begin{array}{c}\mathrm{Ni} \\
\leq 0.50\end{array}$ & $\begin{array}{c}\mathrm{Nb} \\
\leq 0.11\end{array}$ \\
\hline $\mathrm{V}$ & $\mathrm{Ti}$ & $\mathrm{Cu}$ & $\mathrm{B}$ & $\mathrm{Al}$ & $\mathrm{N}$ & $\mathrm{V}+\mathrm{Nb}+\mathrm{Ti}$ & $\mathrm{Pcm}$ & $\mathrm{CE}$ \\
$\leq 0.06$ & $\leq 0.025$ & $\leq 0.30$ & $\leq 0.0005$ & $\leq 0.06$ & $\leq 0.008$ & $\leq 0.15$ & $\leq 0.23$ & $\leq 0.43$ \\
\hline
\end{tabular}

Note: $\mathrm{Pcm}=\mathrm{C}+\mathrm{Si} / 30+(\mathrm{Mn}+\mathrm{Cu}+\mathrm{Cr}) / 20+\mathrm{Ni} / 60+\mathrm{Mo} / 15+\mathrm{V} / 10+5 \mathrm{~B}$

$\mathrm{CE}=\mathrm{C}+\mathrm{Mn} / 6+(\mathrm{Cr}+\mathrm{Mo}+\mathrm{V}) / 5+(\mathrm{Cu}+\mathrm{Ni}) / 15$ 
Tab. 2 Mechanical properties of X80 pipeline steel

\begin{tabular}{ccccccc}
\hline & \multicolumn{2}{c}{ Tensile properties } & \multicolumn{4}{c}{$\begin{array}{c}\text { Charpy impact } \\
\text { toughness }\end{array}$} \\
\hline$R_{m} / \mathrm{MPa}$ & $R_{t 0.5} / \mathrm{MPa}$ & $A / \%$ & $R_{t 0.5} / R_{m}$ & $A_{k v} / J$ & $S A / \%$ & $S A / \%$ \\
$625 \sim 825$ & $555 \sim 690$ & $\geq 16$ & $\leq 0.93$ & $\geq 240$ & $\geq 90$ & $\geq 85$ \\
\hline
\end{tabular}

\section{Microstructure and Structure of X80 Pipeline Steel}

Fig.1 shows the microstructure of X80 pipeline steel [10]. This microstructure is obtained by controlled rolling and accelerated cooling process. The microstructure of X80 pipeline steels is polygonal ferrite and acicular ferrite. X80 pipeline steel obtained general through controlled rolling and cooling has high toughness and strength [11]. The reason is that the ferrite microstructure has high dislocation density, especially the acicular ferrite has the higher dislocation density, and the ultrafine dispersion phases are precipitated on the ferrite matrix and nanoscale precipitates were produced at dislocation tangles. In addition, the cooling rate after hot rolling will have a significant impact on the microstructure and mechanical properties of X80 pipeline steel. When the cooling rate is slower, granular bainite transformation occurs and the strengthening phases are formed. When the cooling rate is faster, the fine grain strengthening effect will produce. With increasing cooling rate after rolling, the hardness of materials is increasing. For X80 pipeline steel, we can see that high strength and high toughness microstructure can be obtained not only by micro-alloyed, but also through the optimization of rolling process and the regulation of cooling rate after hot rolling, so as to obtain the best mechanical properties.

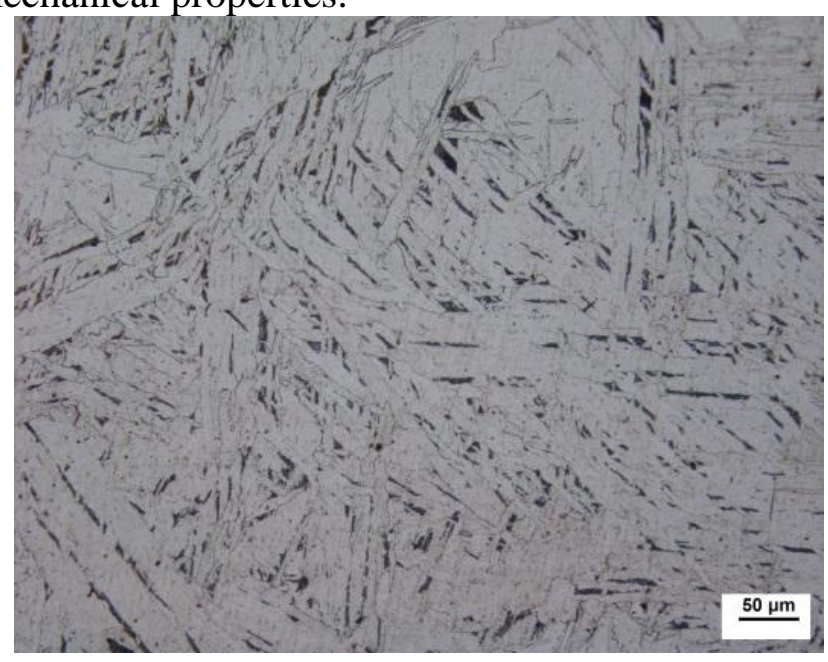

Fig. 1 Microstructure of X80 pipeline steel

X80 pipeline steel with low carbon content and the appropriate micro-alloying, coupled with modern controlled rolling and controlled cooling technology, will have very high strength and toughness. The corresponding solutions to the softening and embrittlement in partial microstructure in the high heat input welding process were presented. Scholars mainly explored the following aspects, such as composite micro-alloying of $\mathrm{Nb}$ and $\mathrm{Ti}, \mathrm{Al}, \mathrm{Ti}, \mathrm{Mg}, \mathrm{Zr}$ alloy oxides and complex oxide micro-alloying and Ca treatment desulfurization technology, and so on.

\section{Conclusions}

The characteristic of chemical composition of X80 pipeline steel, the microstructure and the existing problems under the condition of high heat input welding were introduced in this paper. The micro-alloyed process of $\mathrm{Nb}, \mathrm{Ti}, \mathrm{V}$ elements in X80 pipeline steel and the influence on the mechanical properties were respectively discussed. In addition, the reasons of the grain coarsening in the welding heat affected zone, the softening and embrittlement in partial microstructure were explored and the 
corresponding solutions were presented.

(1) For X80 pipeline steel, we can see that high strength and high toughness microstructure can be obtained not only by micro-alloyed, but also through the optimization of rolling process and the regulation of cooling rate after hot rolling.

(2) X80 pipeline steel with low carbon content and the appropriate micro-alloying, coupled with modern controlled rolling and controlled cooling technology, will have very high strength and toughness. The corresponding solutions to the softening and embrittlement in partial microstructure in the high heat input welding process were presented. Scholars mainly explored the following aspects, such as composite micro-alloying of $\mathrm{Nb}$ and $\mathrm{Ti}, \mathrm{Al}, \mathrm{Ti}, \mathrm{Mg}, \mathrm{Zr}$ alloy oxides and complex oxide micro-alloying and $\mathrm{Ca}$ treatment desulfurization technology, and so on.

\section{Acknowledgments}

This work was supported by the Liaoning Province Natural Science Fund Project (No. 2014020097), the Project for Liaoning Provincial Scientific Research in University of China (No. L2014475) and the Open Subject Fund of the State Key Laboratory of Rolling and Automation of NEU, China (No. 2009003).

\section{References}

[1] X.H. Lin, B.N. Qian, X.M. Guo, Development of submerged arc welding wires for high performance pipeline steel, J. of Iron and Steel Research, International. 4 (2003) 73-76.

[2] M. Pu, J.G. Ma, 2010 new development of oil and gas pipelines in China, International Petroleum Economics. 3 (2011) 26-34.

[3] Y. Zhang, Development of non-conventional oil and gas need to accelerate the pace, Petroleum \& Equipment. 3 (2011) 32.

[4] A.H. Qi, The Twelve-Five development trend analysis of China oil and gas pipeline transportation, Comprehensive Transportation. 4 (2011) 15.

[5] F.X. Huang, Research on internal circumferential automatic welding equipment and process for long distance pipeline with big size, Tianjin University. (2009) 6-7.

[6] H.L. Gao, Microstructure, Properties and Welding of Pipeline Steel, Shanxi Science and Technology Press, Xi'an, 2009.

[7] H. Suzuki, Weldability of modern structural steels, Welding in the World. 20 (1982) 121-147.

[8] M. Shome, D. S. Sarma, O. P. Gupta, Precipitate dissolution and grain growth in the heat affected zone of HSLA-100 steel, ISIJ International. 43 (2003) 1431-1437.

[9] L.L. Zhang, Study on microstructure \& property of X80 pipeline steel used in the second West-East Gas Pipeline Project, Xi'an Shiyou University. (2011) 12-14.

[10] Q.H. Ma, Study on the microstructure and mechanical of X80 pipeline steel by adding nano-oxides in the welding heat affected zone, Shenyang University. (2013) 28-30.

[11] M.C. Zhao, F.R. Xiao, Y.Y. Shan, Microstructural characteristic and toughening of an ultralow carbon acicular ferrite pipeline steel, Acta Metallurgica Sinica. 38 (2002) 283-287. 